\title{
Impacto del tipo de resección (anatómico y no anatómico) en los resultados de la cirugía hepática para el tratamiento de las metástasis colorectales*
}

\author{
Dr. NICOLÁS JARUFE C. ${ }^{1}$ \\ 1 Departamento de Cirugía Digestiva. Pontificia Universidad Católica, Santiago, Chile.
}

\author{
TRABAJO DE INGRESO
}

\begin{abstract}
\end{abstract}
\section{Surgery of liver metastases, anatomical vs non anatomical resections}

Introduction: Surgery of liver metastases has clear benefit in increases survival of patients with colorectal cancer. If resection must be done on anatomical basis or only wedge resection is still in discussion. The objective of this work is to analyze and to compare the anatomical liver resections (RA) versus the notanatomical ones (RNA) in the treatment of liver metastases from colorectal cancer. Material and Method: Retrospective revision of all patients operated by colorectal liver metastases from year 2000 to the 2007 . RA was considered according to the principles of Couinaud and that included one or more liver segments. The sub-segmental or wedge resections were denominated RNA. Results: Of a total of 164 resections 34, $7 \%$ (57) were by colorectal metastases. $61 \%$ were RA, $23 \%$ RNA and $16 \%$ combined. There was $19 \%$ of extended resection (5 or more segments). The global morbidity was $35 \%$ and mortality of $0 \%$. When comparing the different variables, the operating time, blood transfusions, prolongation of the prothrombin time and UCI stay, were significantly greater in the RA with respect to the RNA. On the other hand, there was greater amount of R0 surgeries in RA $(\mathrm{p}<0.05)$. With respect to the bad prognosis criteria, in average the patients with RA had more criteria versus RNA patients $(\mathrm{p}<0.05)$. The actuarial survival was $50 \%$ and $29 \%$ for RA and RNA respectively $(\mathrm{p}=\mathrm{ns})$. The free disease survival was $20 \%$ and $19 \%$ for RA and RNA respectively $(\mathrm{p}=\mathrm{ns})$. Discussion: The anatomical surgery of the liver allows removing a larger number and size of lesions with similar morbidity and mortality. Apparently there would be a benefit in survival in patients with RA but the difference is not significant in this study.

Key words: Colorectal liver metastases, anatomical resections, non anatomical resections.

\section{Resumen}

Introducción: La cirugía resectiva de metástasis hepáticas ha demostrado aumentar la sobrevida especialmente en pacientes con metástasis de origen colorectal. Si deben hacerse resecciones locales o anatómicas está todavía en discusión. El objetivo de este trabajo es analizar y comparar las resecciones hepáticas anatómicas (RA) y las no-anatómicas (RNA) en el tratamiento de las metástasis hepáticas de origen colorrectal. Material y Método: Revisión retrospectiva de todos los pacientes operados por metásta-

*Recibido el 15 de Octubre de 2008 y aceptado para publicación el 22 de Noviembre de 2008.

Correspondencia: Dr. Nicolás Jarufe C.

Marcoleta 367, Santiago, Chile

E-mail: njaruffe@med.puc.cl 
sis hepáticas colorectales desde el año 2000 al 2007. Se consideraron RA a todas aquellas realizadas según los principios de Couinaud y que incluyeran uno a más segmentos hepáticos. Las resecciones subsegmentarias o locales se denominaron RNA. Resultados: De un total de 164 resecciones el 34.7\% (57) son por metástasis colorectales. En $61 \%$ fueron RA, $23 \%$ RNA y $16 \%$ combinadas. Hubo un $28 \%$ de resecciones sincrónicas con el tumor primario. Un 19\% corresponden a resecciones extendidas (5 ó más segmentos). La morbilidad global fue de $35 \%$ y mortalidad de $0 \%$. Al comparar las distintas variables, el tiempo operatorio, el volumen de sangrado, la prolongación del tiempo de protrombina y la estadía en UCI, fueron significativamente mayores en las RA respecto a las RNA. Por otra parte, hubo mayor cantidad de cirugías RO en RA $(p<0,05)$. Respecto a los criterios de mal pronóstico, en promedio los pacientes con RA tuvieron mayor cantidad de criterios respecto a los con RNA $(p<0,05)$. La sobrevida actuarial fue de $50 \%$ y $29 \%$ para RA y RNA respectivamente $(\mathrm{p}=\mathrm{ns})$. La sobrevida libre de enfermedad fue de $20 \%$ y $19 \%$ para RA y RNA respectivamente $(\mathrm{p}=\mathrm{ns})$. Discusión: La cirugía anatómica del hígado permite resecar un mayor número y tamaño de lesiones con similar morbi-mortalidad. Aparentemente habría un beneficio en sobrevida en los pacientes con RA pero la diferencia no es significativa en este estudio.

Palabras clave: Metástasis hepáticas colorectales, resecciones anatómicas, resecciones no anatómicas.

\section{Introducción}

La cirugía del hígado ha presentado importantes avances en las últimas décadas. Esto ha contribuido a mejorar la resecabilidad y por lo tanto, el pronóstico de varias patologías anteriormente intratables $^{1,2}$. El hígado recibe frecuentemente metástasis de enfermedades neoplásicas malignas que representan estados avanzados en los que prevalecen tratamientos de orden paliativos. Sin embargo, en el caso del cáncer de colon y recto, es un hecho que la extirpación de sus metástasis hepáticas y pulmonares cuando puede ser realizado completamente, otorga un beneficio en sobrevida que no ha sido igualado con terapias no quirúrgicas ${ }^{3}$.

La aparición de agentes quimioterápicos de segunda línea y anticuerpos monoclonales contra distintos factores de crecimiento tumoral, han contribuido a mejorar los resultados del tratamiento de las metástasis colorectales ${ }^{4-6}$. Esta clara dependencia de la cirugía en el tratamiento de las metástasis del cáncer de colon y recto, hace necesario que se cumplan estrictas normas técnicas con el objeto de lograr cirugías oncológicas, es decir, sin compromiso de márgenes microscópicos ni lesiones residuales, ya que de lo contrario, el beneficio de la cirugía es nulo ${ }^{7-9}$.

Hoy en día, las resecciones hepáticas para metástasis colorectales están ampliamente aceptadas; sin embargo, aún se discute si deben realizarse sólo resecciones locales y limitadas o anatómicas que habitualmente involucran mayor masa hepática. Un mejor conocimiento de la anatomía del hígado y los francos avances en métodos radiológicos así como también en la técnica quirúrgica y anestésica, han permitido ampliar el rango de indicaciones y la magnitud de las resecciones sin que ello signifique una mayor morbi-mortalidad ${ }^{10-12}$. Es así como las ciru- gías hepáticas regladas que siguen la disposición anatómica de las estructuras del hígado, han ido ganando terreno por sobre las resecciones locales o no anatómicas ya que las primeras permiten resecar mayor masa hepática, alejarse de los bordes tumorales y disminuir el volumen de sangrado y filtraciones post-operatorias al tener un mejor control de los pedículos ${ }^{11-13}$.

El objetivo del presente trabajo es analizar y comparar las resecciones hepáticas anatómicas (RA) versus no-anatómicas (RNA) en el tratamiento de las metástasis hepáticas de origen colorectal, en términos de morbilidad, mortalidad, recurrencia y sobrevida.

\section{Material y Método}

Se realizó una revisión de todos los pacientes sometidos a resecciones hepáticas por metástasis colorectales, desde el año 2003 a julio del 2007. Desde el 2003 a la fecha, existe un registro prospectivo de hepatectomías a través de un protocolo especialmente diseñado que va siendo completado al mismo tiempo con la ficha clínica y la evolución del paciente. Posteriormente, dicho registro es ingresado a una base de datos. Los datos anteriores al 2003 fueron obtenidos de las fichas clínicas y protocolos operatorios.

Se analizó las características demográficas de los pacientes y detalles de la técnica quirúrgica utilizada, así como también datos intraoperatorios que incluyeron tiempo total de cirugía, tiempo de isquemia o clampleo del pedículo (maniobra de Pringle) y uso de hemoderivados. En el postoperatorio se midió en forma diaria los niveles de transaminasas, protrombina y bilirrubina por al menos 5 días o hasta que la ictericia comienza a resolverse. Se registra- 
ron complicaciones, mortalidad y días totales de hospitalización. Morbilidad postoperatoria fue definida como cualquier complicación ocurrida durante el período de hospitalización y hasta 3 meses post cirugía. Mortalidad operatoria fue definida como aquella producida durante la cirugía, dentro de los 30 días postoperatorios o en la misma hospitalización independientemente de que ésta sea mayor a 30 días. Bilirragia se definió como salida de contenido bilioso por los drenajes mantenido por al menos 72 horas y no más de 7 días, posterior a los cuales se catalogó como fístula biliar. Disfunción hepática postoperatoria se definió como prolongación del tiempo de protrombina sobre 18 segundos o bilirrubina plasmática sobre $2 \mathrm{mg} / \mathrm{dl}$. Insuficiencia hepática fue definida como niveles de bilirrubina persistentemente elevados por sobre $6 \mathrm{mg} / \mathrm{dl}$, tiempo de protrombina sobre 24 segundos que hace necesario el aporte diario de plasma fresco congelado y elevación de transaminasas asociado a encefalopatía.

Se consideraron RA todas aquellas que fueron realizadas siguiendo los principios de Couinaud y que incluyeran 1 ó más segmentos hepáticos. Las resecciones sub-segmentarias o que no siguieron estrictamente la anatomía hepática segmentaria de Couinaud, fueron consideradas resecciones locales, metastasectomía o RNA. Las resecciones combinadas (RA + RNA) fueron incluidas dentro del primer grupo (RA). No hubo randomización para la selección del tipo de resección, sino más bien éste dependió de la extensión de la enfermedad y elección del cirujano. El abordaje del pedículo para las RA, fue realizado con técnica extrahiliar y suprahiliar, según preferencia del cirujano y ampliamente detalladas en una publicación anterior ${ }^{14}$. En los casos en que se usó maniobra de Pringle, esta se realizó de manera intermitente por períodos de 15 a 20 minutos y 10 minutos de pausa. La transección del parénquima fue realizada siguiendo la línea de demarcación isquémica en las RA. Para las RNA, se intentó siempre incluir al menos $1 \mathrm{~cm}$ de margen en tejido hepático sano, desde el borde de la lesión. El hígado fue dividido ya sea con bisturí ultrasónico (Ultrasicion, Harmonic scalpel), Kellyclasia, electrofulguración o Ligasure, según preferencia del cirujano. En todos los casos se realizó ecografía intraoperatoria que ayudó a definir el tamaño, ubicación y número de las lesiones así como también las relaciones anatómicas del tumor con los vasos y conductos biliares.

En todos los casos se calculó el número de criterios pronósticos según el Memorial SloanKettering ${ }^{8}$.

Se compararon las RA con las RNA. Se calcularon sobrevidas actuariales y libre de enfermedad hepática para ambos grupos. Se compararon variables de la cirugía, anatomía patológica y de laboratorio durante el post-operatorio.

Análisis Estadístico. El análisis estadístico fue realizado con el programa Statview 5.0.1 y Minitab 15. Se calculó la sobrevida y período libre de enfermedad con el método de Kaplan-Meier y se utilizó el test de log-rank para comparación. Las variables se compararon con test de student y chi-cuadrado según correspondiera, considerándose significativo un $\mathrm{p}<0,05$. Los datos se expresan en promedio \pm desviación Standard o mediana (rango).

\section{Resultados}

Durante los 6 años y medio del estudio se realizaron 164 resecciones hepáticas de las cuales, 57 $(34,7 \%)$ corresponden a metástasis colorectales en 49 pacientes (35 hombres y 14 mujeres). La edad promedio fue de $60 \pm 13$ años. El tumor primario se ubicó en el colon en 35 (71\%) pacientes y en el recto en 14 pacientes (29\%). El cáncer primario presentó ganglios positivos en un $63 \%$.

En 8 pacientes se realizaron re-resecciones, 7 por recurrencia hepática exclusiva y 1 por hepatectomía programada en 2 tiempos. En un caso fue necesario embolizar la porta derecha previo a una resección extendida como un mecanismo para aumentar el volumen de hígado remanente.

En $35(61 \%)$ casos se realizó una RA, en 13 (23\%) casos una resección local, y en $9(16 \%)$ procedimientos combinados (RA + RNA). En el grupo de RA se resecaron 3,2 $\pm 1,5$ segmentos por cirugía y se realizaron $11(19 \%)$ resecciones extendidas, de 5 o más segmentos de Couinaud (Tabla 1). En 16 (28\%) casos la resección hepática se realizó en forma sincrónica con la cirugía colorrectal. En un caso

Tabla 1. Resecciones hepáticas por metástasis colorrectal

\begin{tabular}{lrr}
\hline Resección hepática & n & \% \\
\hline Hepatectomía derecha* & 13 & 23 \\
Hepatectomía derecha extendida & 11 & 19 \\
Segmentectomía 2,3 & 6 & 10 \\
Segmentectomía 6,7 & 5 & 9 \\
Hepatectomía izquierda & 1 & 2 \\
Segmentectomías (Otras) & 8 & 14 \\
No Anatómica (Resección local) & 13 & 23 \\
Total & 57 & 100 \\
\hline
\end{tabular}


Tabla 2. Comparación de pacientes con resección anatómica y no-anatómica

\begin{tabular}{|c|c|c|c|}
\hline & Anatómica & No-Anatómica & $\mathbf{p}$ \\
\hline Edad (años) & $59 \pm 14$ & $64 \pm 8$ & ns \\
\hline Sexo (hombres) & $61 \%$ & $90 \%$ & $\mathrm{~ns}$ \\
\hline Ubicación tumor (colon) & $68 \%$ & $81 \%$ & ns \\
\hline Segmentos resecados & $3,5 \pm 1,3$ & $0 \pm 0$ & $<0,0001$ \\
\hline Resección sincrónica (\%) & $29 \%$ & $36 \%$ & ns \\
\hline Tiempo operatorio (min) & $243 \pm 77$ & $174 \pm 89$ & 0,016 \\
\hline Clampeo portal $(\%)$ & $35 \%$ & $20 \%$ & ns \\
\hline Clampeo portal (min) & $8 \pm 15$ & $3 \pm 10$ & ns \\
\hline Sangrado operatorio (ml) & $907 \pm 749$ & $338 \pm 293$ & 0,032 \\
\hline Transfusión de GR (\%) & $39 \%$ & $0 \%$ & 0,011 \\
\hline Unidades de GR & $0,7 \pm 1,0$ & $0 \pm 0$ & 0,019 \\
\hline Peak de SGOT & $415 \pm 398$ & $270 \pm 223$ & ns \\
\hline Peak de SGPT & $391 \pm 346$ & $381 \pm 447$ & $\mathrm{~ns}$ \\
\hline Peak de Bilirrubina ( ) & $2,2 \pm 2,6$ & $1,3 \pm 0,4$ & ns \\
\hline Peor TP $(\%)$ & $48 \pm 16 \%$ & $65 \pm 11 \%$ & 0,017 \\
\hline Complicaciones (\%) & $42 \%$ & $9 \%$ & ns \\
\hline Hospitalización (días) & $11 \pm 6$ & $8 \pm 3$ & ns \\
\hline Estada UCI $(\%)$ & $39 \%$ & $0 \%$ & 0,011 \\
\hline Peso pieza quirúrgica (grs) & $736 \pm 663$ & $47 \pm 41$ & 0,009 \\
\hline Lesiones resecadas (n) & $2,7 \pm 2,6$ & $1,3 \pm 0,5$ & ns \\
\hline Tamaño lesión mayor (cms) & $6,5 \pm 5,6$ & $2,9 \pm 1,5$ & 0,042 \\
\hline \multicolumn{4}{|l|}{ Resultado de la cirugía } \\
\hline R0 & $3695 \%$ & $545 \%$ & 0,0007 \\
\hline $\mathrm{R} 1$ & 1 & 2 & \\
\hline $\mathrm{R} 2$ & 1 & 4 & \\
\hline Puntaje MSK 2 o más & $79 \%$ & $45 \%$ & 0,03 \\
\hline QMT segunda línea & $53 \%$ & $55 \%$ & ns \\
\hline
\end{tabular}

GR: Glóbulos rojos. TP: Tiempo de protrombina. MSK: Memorial Sloan Kettering.

se realizó una hepatectomia derecha completamente laparoscópica.

El tiempo operatorio fue de $227 \pm 89(\mathrm{~min})$ y el sangrado de $823 \pm 766 \mathrm{ml}$ para el total de las cirugías. Se realizaron transfusiones de glóbulos rojos en el intraoperatorio en un $30 \%$ de las cirugías, en promedio $1,8 \pm 0,6$ unidades por cirugía. Se utilizó clampeo portal en $32 \%$ de las resecciones, con una duración de $30 \pm 16 \mathrm{~min}$ (rango 5-60 min). Los valores comparativos de detalles peri-operatorios se aprecian en la Tabla 2.

La estadía hospitalaria fue de $10 \pm 6$ días, y 16 (28\%) de las resecciones requirieron estadía en Cuidados Intensivos, en promedio 2 días (rango 1-5).

La morbilidad fue de $35 \%$, destacando: colecciones intra-abdominales $6(11 \%)$, fístula biliar $5(9 \%)$, insuficiencia hepática $4(7 \%)$ y hemoperitoneo 3
(3\%). Se reoperaron 4 pacientes, 3 por hemoperitoneo y uno por una colección intrabdominal (Tabla 3). Las colecciones intrabdominales se trataron con antibióticos en 3 casos, con una punción percutánea en 2 y con una reoperación en 1 paciente. Las fístulas biliares se trataron en forma conservadora a través del drenaje. Cuatro pacientes cumplieron los criterios de falla hepática, esta fue autolimitada y respondió con manejo médico. No hubo mortalidad peri-operatoria en esta serie.

En $4(8 \%)$ pacientes con RA se detectaron en la pieza quirúrgica lesiones no diagnosticadas con el estudio preoperatorio.

El seguimiento se logró en el $100 \%$ de los pacientes con 24 meses de promedio (4-92); 33 (67\%) pacientes se encuentran vivos con 27 (4-92) meses de seguimiento y $16(33 \%)$ pacientes fallecieron a 
los 17 (5-55) meses de seguimiento. La sobrevida global actuarial a 5 años fue de $46 \%$, con una mediana de sobrevida de 55 meses (Figura 1). Para los pacientes con una cirugía R0 la sobrevida actuarial a 5 años fue $47 \%$ con una mediana de 55 meses, para los pacientes R1 ó R2 esta fue de $29 \%$ con una mediana de 20 meses $(p=0,047)$ (Figura 2).

Tabla 3. Complicaciones de las resecciones hepáticas

\begin{tabular}{lrr}
\hline Complicación & n & \% \\
\hline Colección intrabdominal & 6 & 11 \\
Fístula biliar & 5 & 9 \\
Insuficiencia hepática & 4 & 7 \\
Hemoperitoneo & 3 & 5 \\
Infección herida & 1 & 2 \\
Neumonia & 2 & 4 \\
Fistula intestinal & 1 & 2 \\
Evisceración & 1 & 2 \\
Empiema & 1 & 2 \\
Trombosis venosa profunda & 1 & 2 \\
Shock anafiláctico & 1 & 2 \\
Síndrome coronario & 1 & 2 \\
Hemorragia digestiva baja & 1 & 2 \\
Neumotórax & 1 & 2 \\
Total casos con complicaciones & 20 & 35 \\
\hline
\end{tabular}

Dieciséis pacientes presentaron recurrencia hepática de su enfermedad con un seguimiento al momento de la aparición de la recurrencia de 15 meses (2-41), como ya se mencionó 7 de estos pacientes fueron re-resecados, mientras que 9 pacientes no fueron candidatos a una re-resección ya sea por enfermedad diseminada y/o magnitud del compromiso hepático. En los 7 pacientes que fueron a una re-resección se logró una cirugía con intención curativa (R0), estos pacientes están vivos con un seguimiento de 35 meses (25-91). Seis pacientes fallecen con recidiva en otros sitios, pero sin evidencia de recidiva hepática. Veintidós pacientes están vivos y sin recidiva hepática con un seguimiento de 21 meses (4-92). La sobrevida actuarial libre de enfermedad hepática es de $20 \%$ a 5 años, con una mediana de sobrevida sin recidiva de 28 meses (Figura 3 ).

Los factores pronósticos de Memorial SloanKettering ${ }^{8}$ presentes en los pacientes fueron ganglios (+) en el tumor primario (63\%), intervalo de la cirugía colónica y hepática menor a un año en 27 pacientes $(55 \%)$, más de una metástasis en 27 (55\%), tumor mayor a $5 \mathrm{~cm}$ en $21(43 \%)$ y CEA sobre $200 \mathrm{ng} / \mathrm{ml}$ en 7 pacientes (15\%), el valor de CEA no estuvo disponible para revisión en 3 pacientes. El número promedio de factores pronósticos fue $2,3 \pm 1,2$ y $23(47 \%)$ de lo pacientes presentaron 3 o más factores pronósticos.

La sobrevida actuarial global a 5 años fue de $50 \%$ en los pacientes con RA y $29 \%$ en los con RNA ( $\mathrm{p}=\mathrm{ns}$ ) (Figura 4) y la sobrevida actuarial libre de enfermedad fue de $20 \%$ vs $19 \%$ RA vs RNA respectivamente $(\mathrm{p}=\mathrm{ns})$ (Figura 5).

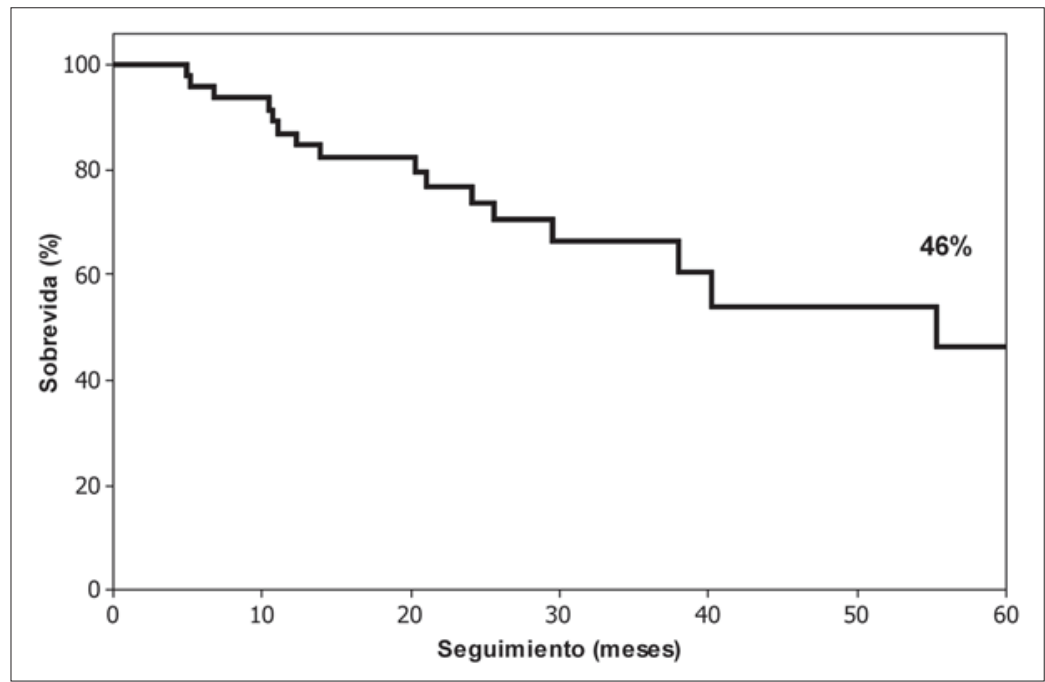

Figura 1. Sobrevida actuarial global. 


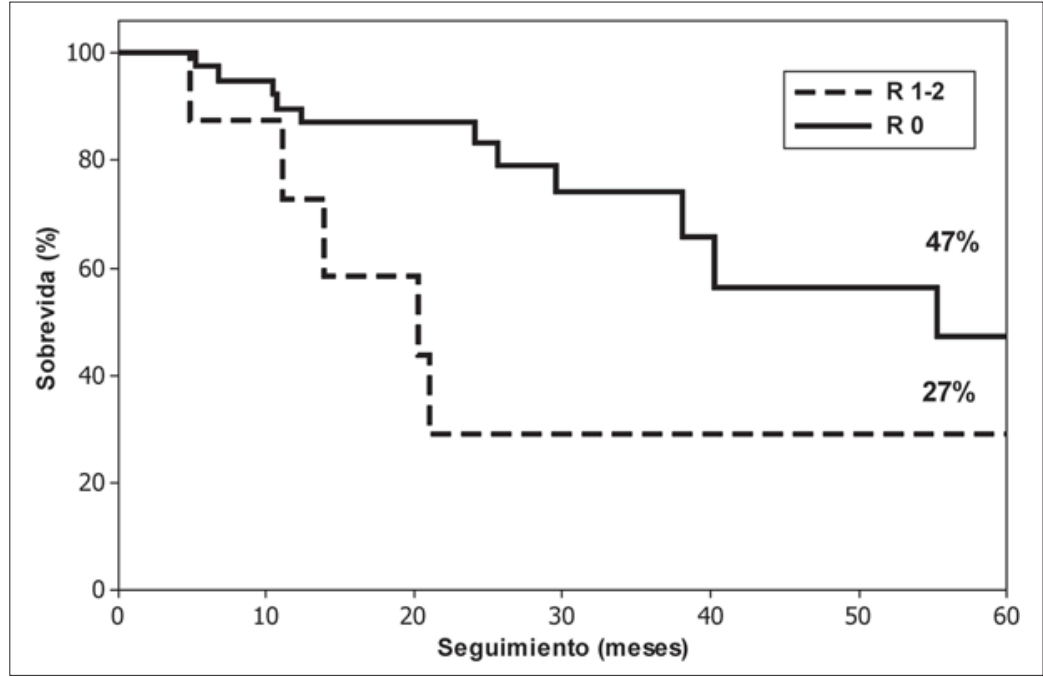

Figura 2. Sobrevida actuarial según el tipo de cirugía realizada.

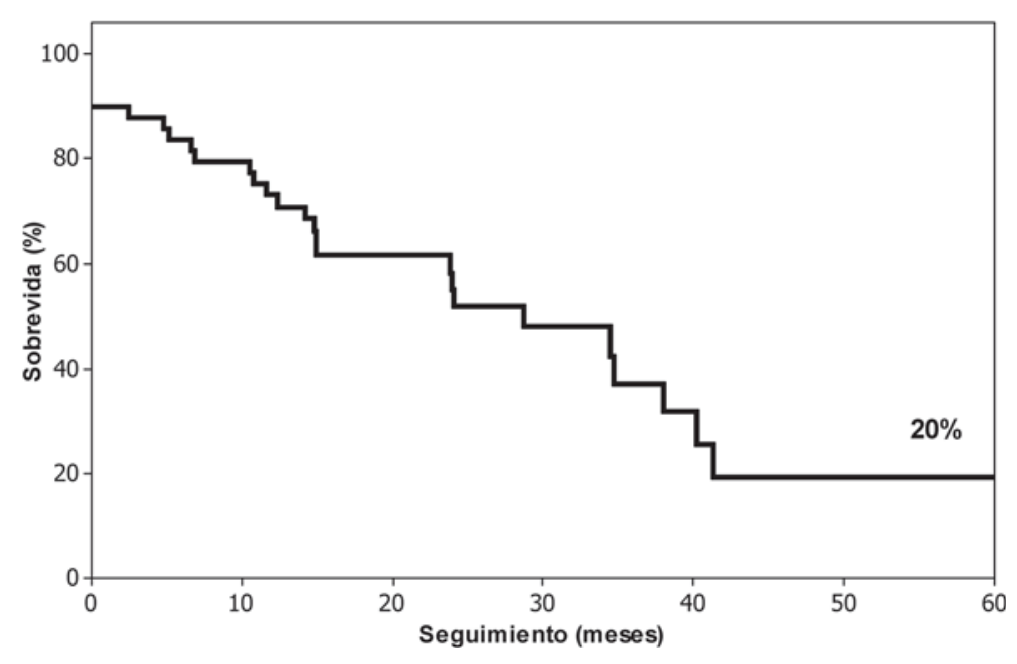

Figura 3. Sobrevida libre de enfermedad hepática.

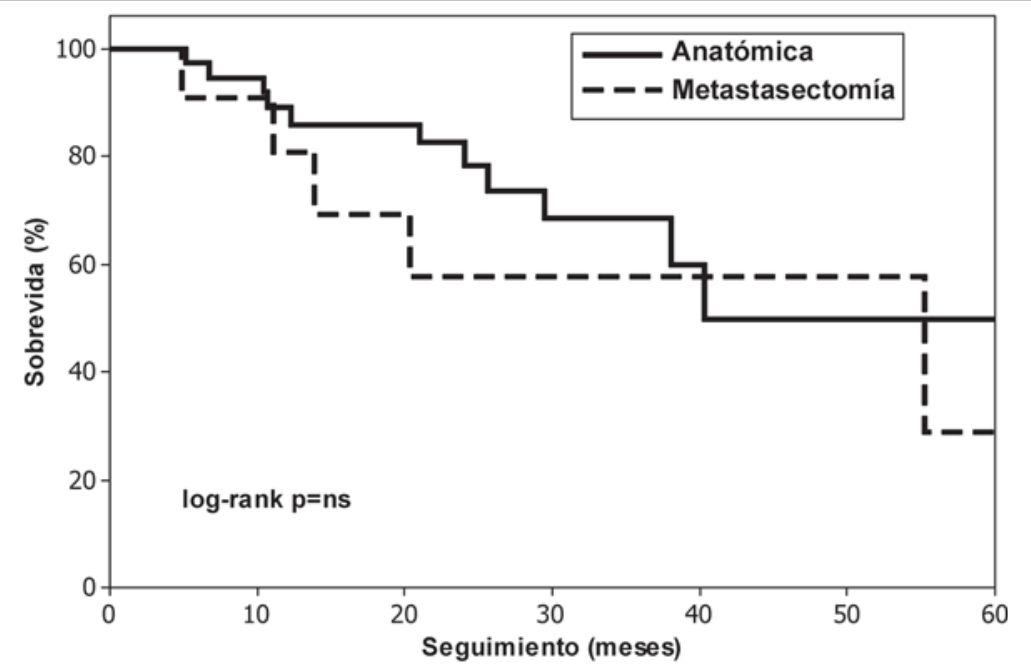

Figura 4. Sobrevida actuarial según tipo de cirugía; anatómica vs metastasectomía. 


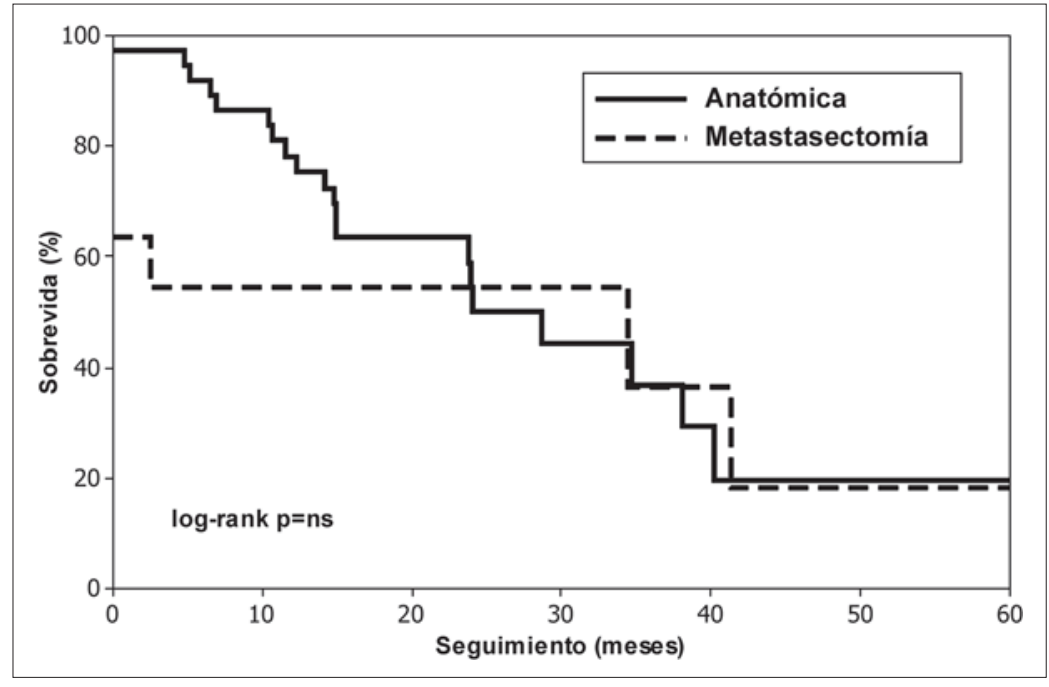

Figura 5. Sobrevida libre de enfermedad hepática según tipo de cirugía; anatómica y metastasectomía.

\section{Discusión}

La resección hepática constituye la única alternativa potencialmente curativa para el tratamiento de las metástasis hepáticas de origen colorectal, con sobrevidas actuales de 35 a $58 \%$ en casos sometidos a cirugías con intención curativa ${ }^{15-17}$. En el pasado, no se realizaba cirugía en pacientes con más de 3 ó 4 metástasis, presencia de linfonodos hiliares o invasión de grades vasos, así como tampoco en aquellos con metástasis pulmonares sincrónicas. Estudios más recientes confirman que más que el número o tamaño de las metástasis e incluso la invasión de estructuras vecinas, lo que marca el pronóstico es la capacidad o no de ser resecadas con márgenes libres $(\mathrm{R} 0)^{8,9,15-17}$.

El presente trabajo demostró valores de sobrevida similares a los internacionales con aparente mejores resultados cuando las intervenciones fueron anatómicas en vez de locales. Es interesante remarcar que la mayoría de las resecciones anatómicas los pacientes eran portadores de mayor número y tamaño de las metástasis que en aquellos donde las resecciones fueron limitadas. Aún considerando que las anatómicas conllevan una mayor extracción de masa hepática, las morbilidades fueron similares y no se presentaron insuficiencias hepáticas graves o mortalidad incluso en resecciones extendidas. Lo anterior se explica en parte por el hecho de que todos los pacientes con metástasis colorrectal en este estudio tenían ausencia de daño hepático crónico, al contrario de lo que ocurre en la mayoría de los pacientes con tumores primarios del hígado.
El potencial de regeneración hepática se produce de regla en los pacientes a los que han sido sometidos a algún tipo de resección. Esta regeneración comienza entre el día 5 al 7 post-operatorio consolidándose a los 3 meses. Por lo tanto, aunque se haya practicado una resección extendida de hígado, el paciente tendrá función e incluso tamaño hepático adecuado para una calidad de vida normal o futuras re-resecciones ${ }^{11,18,19}$. Otro punto a destacar es que la sobrevida libre de enfermedad en los casos de resecciones anatómicas es mayor que los no anatómicos, hecho explicado probablemente por los casos de compromiso microscópico de los bordes (R1) y la presencia de lesiones no detectadas que aparecen incidentalmente en las resecciones anatómicas (4 casos en este estudio) y que eventualmente quedan in situ cuando la cirugía se limita a resecciones locales ${ }^{13,20,21}$. Por lo tanto, hoy en día la definición de resecabilidad de las MCR ya no debería estar basada por las características de las metástasis (tamaño, número, localización, etc), sino por la posibilidad de dejar al paciente libre de enfermedad microscópica en el hígado y la resección completa de estructuras adyacentes comprometidas ${ }^{8}$. Incluso la resección sincrónica o metacrónica de metástasis pulmonares cuando es posible, también se considera criterio potencialmente curativo ya que la sobrevida es mayor que con terapias no quirúrgicas 22 .

Para cumplir con esta nueva definición de resecabilidad, se deben lograr los siguientes principios: deben quedar al menos 2 segmentos hepáticos, el volumen mínimo de parénquima residual, debe ser $>20 \%$ del volumen total del hígado y fi- 
nalmente el flujo portal, arterial y los drenajes biliar y venoso, deben ser respetados en los segmentos residuales. En casos de hepatectomías extendidas en que el volumen residual calculado no va a ser suficiente, están indicados procedimientos tendientes a hipertrofiar el lóbulo contralateral como embolización de la porta derecha, rara vez la izquierda ya que el volumen de los segmentos posteriores para hepatectonías izquierdas extendidas casi siempre es superior al $30 \%$ del volumen total a diferencia de los segmentos laterales izquierdos ${ }^{9}$. Alternativamente se pueden programar resecciones en 2 etapas sustentado por la regeneración hepática postresección ${ }^{23,24}$. En esta serie sólo un paciente necesitó embolización portal y posterior resección extendida exitosa. El resto de las resecciones extendidas fueron realizadas considerando una volumetría con $25 \%$ o más de volumen de parénquima hepático residual. La morbilidad y mortalidad de la serie está dentro de los parámetros de los centros de gran volumen de cirugía hepática destacando el $0 \%$ de mortalidad obtenido pese a la magnitud de las resecciones realizadas (19\% de resecciones de 5 ó más segmentos).

Si bien no existen datos claros en la literatura de si las resecciones anatómicas tienen finalmente mejor sobrevida, si logran claramente mejores índices de márgenes negativos (significativo en esta serie), siendo ésta una de las variables más importantes en el pronóstico del paciente ${ }^{13,20,21}$. Sin embargo, no todas las lesiones deben ser tratadas con resecciones basadas en la segmentación hepática. En metástasis pequeñas y superficiales, probablemente una resección local con márgenes negativos, es la mejor opción. Pero por otra parte, tumores de mayor tamaño y profundidad, la resección anatómica ofrece más radicalidad oncológica e incluso mayor seguridad operatoria al tener mejor control pedicular.

Otro punto controversial es si el margen debe ser mayor a $1 \mathrm{~cm}$ de tejido sano o basta con que éste sea negativo. Al respecto existen estudios de sobrevida que avalan ambas aseveraciones. La conducta debiera ser similar a otras cirugías oncológicas en el sentido de no buscar el mínimo margen pero por otro lado, no contraindicar una resección completa cuando no sea posible alcanzar un margen de $1 \mathrm{~cm}^{8,9,15}$.

En esta serie sólo la mitad de los casos recibió tratamiento adyuvante o neoadyuvante, sin embargo, la evidencia actual es cada vez más clara en el beneficio de estas terapias en términos de sobrevida para cáncer colorectal metastático ${ }^{4-6}$. Los resultados con o sin quimioterapia no fueron evaluados específicamente en este trabajo.

En conclusión la cirugía anatómica del hígado permite resecar en forma completa y con mejores márgenes, un mayor número de lesiones y de mayor tamaño que las RNA. Tiene la desventaja de una mayor morbilidad, tiempo operatorio y sangrado pero sin repercusiones en la evolución final de los pacientes. A pesar de que el grupo con RA es teóricamente de peor pronóstico en esta serie, no hubo diferencias de sobrevida con los RNA con similares tasas de recurrencia. Finalmente, la evaluación de los pacientes debe ser realizada por un equipo multidisciplinario y el tratamiento quirúrgico por cirujanos con experiencia hepato-biliar y en centros especializados en cirugía de alta complejidad.

\section{Referencias}

1. Belghiti J, Hramatsu K, Benoist S, Massault PP, Sauvanet A. Seven hundred forty-seven hepatectomies in the 1990s: An update to evaluate the actual risk of liver resection. J Am Coll Surg 2000; 191: 38-46.

2. Jarnagin W, Gonen M, Fong Y, Dematteo R, BenPorat L, Little S, et al. Improvement in perioperative outcome after hepatic resection: analysis of 1803 consecutives cases over the past decade. Ann Surg 2002; 236: 397-406.

3. Pawlik TM, Choti MA. Surgical therapy for colorectal metastases to the liver. J Gastrointest Surg 2007; 11: 1057-1077.

4. Saltz L, Cox J, Blanke C, Rosen L, Fehrenbacher L, Moore M, et al. Irinotecan plus fluoracil and leucovorin for metastasic colorectal cancer. Irinotecan Study Group. N Engl J Med 2000; 343: 905-914.

5. Adam R, Delvart V, Pascal G, Valeanu A, Castaing D, Azoulay D, et al. Rescue surgery for unresectable colorectal liver metastases downstaged by chemotherapy: a model to predict long-term survival. Ann Surg 2004; 240: 644-657; discussion 520-522.

6. Ribero D, Wang H, Donadon M, Thomas MB, Eng C, Chang DZ, et al. Bevacizumab improves pathologic response and protects against hepatic injury in patients treated with oxaliplatin-based chemotherapy for colorectal liver metastases. Cancer 2007; 110: 27612767.

7. Vauthey JN. Colorectal liver metastases: Treat effectively up front and consider the borderline resectable. J Clin Oncol 2007; 25: 4524-4601.

8. Fong Y, Fortner J, Sun RL, Brennan MF, Blumgart LH. Clinical store for predicting recurrence alter hepatic resection for metastatic colorectal cancer: análisis of 1001 consecutive cases. Ann Surg 1999; 230:309-318; discussion 318-321.

9. Nordlinger B, Guiguet M, Vaillant JC, Balladur P, Boudjema K, Bachellier P, et al. Surgical resection of colorectal carcinoma metastases to the liver. A 
prognostic scoring system to improve case selection, based on 1568 patients. Association Francaise de Chirurgie. Cancer 1996; 77: 1254-1262.

10. Jarnagin W, Gonen M, Fong Y, DeMatteo R, BenPorat L, Little $\mathrm{S}$, et al. Improvement in perioperative outcome after hepatic resection. Analysis of 1803 consecutive cases over the past decade. Ann Surg 2002; 236: 397-407.

11. Vauthey JN, Pawlik TM, Abdalla EK, Arens JF, Nemr RA, Wei SH, et al. Is extended hepatectomy for hepatobiliary malignancy justified? Ann Surg 2004; 239: 722-730; discussion 730-722.

12. Zorzi D, Mullen JT, Abdalla EK, Pawlik TM, Andres A, Muratore A, et al. Comparison between hepatic wedge resection and anatomic resection for colorectal liver metastases. J Gastrointest Surg 2006; 10: 86-94.

13. Dematteo R, Palese C, Jarnagin W, Sun R, Blumgart $\mathrm{L}$, Fong $\mathrm{Y}$. Anatomic segmental hepatic resection is superior to wedge resection as an oncologic operation for colorectal liver metastases. J Gastrointest Surg 2000; 4: 178-184.

14. Jarufe N, Martínez J, Guzmán S, Pacheco F, Guajardo M, Ibáñez L. Técnica de resecciones hepáticas con disección suprahiliar del pedículo. Rev Chil Cir 2005; 57: 462-469.

15. Stangl R, Altendorf-Hofmann A, Charnley R, Scheele J. Factors influencing the natural history of colorectal liver metastases. Lancet 1994; 343: 1405-1410.

16. Butte JM, Jarufe N, Bellolio F, Zuñiga A, López F, Pinedo G, et al. Factores pronósticos de pacientes con metástasis hepáticas de cáncer de colon y recto. Rev Chil Cir 2007; 59: 293-298.

17. Gayowski TJ, Iwatsuki S, Madariaga JR, Selby R, Todo $\mathrm{S}$, Irish $\mathrm{W}$, et al. Experience in hepatic resection for metastatic colorectal cancer: analysis of clinical and pathological risk factors. Surgery 1994; 116: 703-711.

18. Guerra JF, Jarufe N, Martínez J, Guzmán S, Pacheco F, Guajardo M, et al. Hepatectomía extendida. Una alternative segura en lesions hepatobiliares malignas. Rev Chil Cir 2007; 59: 430-435

19. Abdalla EK, Barnett CC, Doherty D, Curley SA, Vauthey JN. Extended hepatectomy in patients with hepatobiliary malignancies with and without preoperative portal vein embolization. Arch Surg 2002; 137: 675-680.

20. Yasui K, Shimisu Y. Surgical treatment for metastatic malignancies. Anatomical resection of liver metastasis: indications and outcome. Int J Clin Oncol 2005; 10: 86-96.

21. Kokudo N, Tada K, Seki M, Otha H, Azekura K, Ueno $\mathrm{M}$, et al. Anatomical major resection versus nonanatomical limited resection for liver metastases from colorectal carcinoma. Am J Surg 2001; 181: 153-159.

22. Mineo TC, Ambrogi V, Tonini G, Bollero P, Roselli $\mathrm{M}$, Mineo D,et al. Long term results alter resection of simultaneous and sequential lung and liver metastases from colorectal carcinoma. J Am Coll Surg 2003; 197 : 386-391.

23. Adam R, Bismuth H, Castaing D, Waechter F, Navarro F, Abascal A, et al. Repeat hepatectomy for colorectal liver metastases. Ann Surg 1997; 225: 5160; discussion 60-52.

24. Petrowsky H, Gonen M, Jarnagin W, Lorenz M, DeMateo R, Heinrich S, et al. Second liver resections are safe and effective treatment for recurrent hepatic metastases from colorectal cancer: a bi-institutional analysis. Ann Surg 2002; 235: 863-871.

\section{INFORME TRABAJO DE INGRESO}

Quiero agradecer a la Sociedad de Cirujanos de Chile por encomendarme comentar el trabajo de ingreso del Dr. Nicolás Jarufe Cassis, titulado "Impacto del tipo de resección (anatómica y no anatómica) en los resultados de la cirugía hepática para el tratamiento de las mestástasis colorrectales".

Fue Prometheus, gran benefactor de la humanidad, llevado a las gélidas cumbres del Cáucaso, encadenado por Hefesto en castigo ordenado por Zeus. Envió Zeus luego un águila monstruosa para que devorara el hígado de Prometheus. Siendo éste inmortal, el águila devoraba su hígado cada noche y éste le volvía a crecer cada día. Como si anticipando la propiedad de este maravilloso órgano de regenerarse en determinadas circunstancias, que nos ha permitido de la mano del desarrollo de la técnica quirúrgica, el cuidado perioperatorio y el progreso de la biología y farmacología, realizar tratamientos más radicales. Esto ha impactado en nuestros pacientes, ofreciéndoles muchas veces una mayor posibilidad de erradicar la enfermedad aunque ésta se encuentre más avanzada en su evaluación inicial.

Prometheus es también asociado con la perpetua búsqueda del conocimiento y del saber, definiciones que también nos reúnen hoy para darle la bienvenida al Dr. Jarufe a nuestra Sociedad.

El trabajo presentado por el Dr. Jarufe hoy constituye una valiosa experiencia que refleja el aporte de un equipo de gran prestigio y consolidación en 
la cirugía digestiva de nuestro país. Versa sobre una serie de casos de 57 pacientes con metástasis hepáticas de primarios colorrectales. En más del $60 \%$ se realizó resección anatómica, en alrededor del $25 \%$, no anatómica y el resto como combinación de ambas. En alrededor de 1/3 de los casos, la cirugía hepática fue sincrónica con la colorrectal. Esta proporción es similar a la reportada por grandes series de la literatura médica. El tiempo operatorio, hemorragia y necesidad transfusional, estadía hospitalaria y complicaciones son comparables con los reportes internacionales. Es muy destacable la ausencia de mortalidad perioperatoria en esta serie.

Es también destacable el $100 \%$ de seguimiento logrado, con sobrevida actuarial y libre de enfermedad comparable con aquellos reportados en la literatura médica. Aquellos pacientes elegibles para reresección post recurrencia evolucionan favorablemente con 35 meses de seguimiento promedio.

En resumen, el Dr. Jarufe ha mostrado que el tratamiento de la enfermedad metastásica colorrectal del hígado en su centro es segura y con resultados comparables a los internacionales.

Existe creciente información con nuevas terapias y en el futuro asistiremos a la aparición de otras series grandes de pacientes con seguimiento más alejado sometidas a terapia neo y coadyuvante que incluyan Irinotecan, Oxaliplatino, Cetuximab, Cevacizumab, terapia con moléculas, hiperplasia hepática preoperatoria por embolización o ligadura portal que es posible cambien algunos conceptos de los resultados a largo plazo de esta enfermedad. En este escenario, tal vez si la única recomendación que me permito hacer es intentar establecer protocolos prospectivos, para evitar la limitación y posible sesgo de un trabajo retrospectivo en la comparación de dos técnicas. Es posible, por ejemplo, que el perfil de un paciente asociado a pronóstico sea ventajoso en el grupo sometido a resecciones no anatómicas o que se haga cirugía "menos radical" en un paciente que "no es buen candidato a cirugía". Esto podría neutralizar la posible ventaja oncológica de las resecciones anatómicas. Es un desafío que el Dr. Jarufe y su grupo pueden enfrentar con creces y enseñarnos en el futuro sus resultados.

Señor Presidente: El Dr. Jarufe, cirujano digestivo de 39 años, estudió medicina en la Universidad de Chile y tras un período como General de Zona realizó su residencia de cirugía general en la misma institución. Luego inicia su período en la Pontificia Universidad Católica cumpliendo con la formación en cirugía digestiva para posteriormente especializarse en cirugía hepatobiliar en la Universidad de Birmingham, Reino Unido, entre los años 2001 y 2003. Regresa a la Pontificia Universidad Católica de Chile y desde entonces ha contribuido indiscutiblemente en el desarrollo de la cirugía digestiva y el programa de trasplante hepático de esa institución. El carácter docente y la extraordinaria inquietud científica del Dr. Jarufe son ilustrados por numerosos proyectos de investigación y múltiples publicaciones y presentaciones científicas, tanto en Chile como en el extranjero, además de membrecías en varias Sociedades Científicas.

Recientemente, el Dr. Jarufe ha sido promovido a la jefatura del Departamento de Cirugía Digestiva de su institución, desde donde sin duda efectuará una gran labor y decisiva para aportar al desarrollo de la cirugía chilena.

Señor Presidente: He tenido también el privilegio de conocer personalmente al Dr. Jarufe desde hace algunos años y quiero también aquí destacar sus extraordinarias cualidades personales que lo hacen un líder natural, muy respetado por sus pares y muy querido por sus amigos.

En suma, el Dr. Jarufe, autor del destacado trabajo aquí presentado, tiene con creces los méritos personales y profesionales para pertenecer a nuestra sociedad como miembro titular y su aporte sin duda la engrandecerá. Recomiendo en forma absoluta su ingreso. Gracias.

Dr. Franco Innocenti $C$. Sanatorio Alemán, Concepción, Chile. 